\title{
SOCIO-ECONOMIC AND ENVIRONMENTAL ASPECTS OF FARMING PRACTICES IN THE PERI-URBAN HINTERLANDS OF NEPAL
}

\author{
Gopal Datt Bhatta, MSc ${ }^{1}$ and Werner Doppler, $\mathrm{PhD}^{2}$
}

\begin{abstract}
Spatial location of the farm households shapes farming practices and livelihoods of the farmers. Many socio-economic variables have strong spatial relations that would otherwise be missed by data aggregation at household level. Geographic Information System (GIS) provides display and analysis of socio-economic data that may be fundamental for many social scientists to understand socio-economic reality influenced by geographical position of the farm households. Present article aims at integrating socio-economic data into GIS environment to examine spatial relation in the resource availability and use employing spatial and random sampling techniques. Result demonstrates the variation in the socioeconomic attributes along the spatial gradient which is mainly related to the infrastructures such as road, market and improved agro-inputs. While households with better access to these infrastructures have tendency to use more agro-chemicals, have larger family, land holding and livestock units, better off-farm opportunities, commercial farming orientation and hence higher family income; opposite is true for the households with poor access to these infrastructures. Peri-urban farmlands, wherever agro-chemicals are applied imprudently, faces the problems of agro-ecological degradation while rural subsistence farming faces the problem of spatial poverty.
\end{abstract}

Key words: Data integration, GIS, Nepal, peri-urban area, spatial explicit assessment

\section{INTRODUCTION}

Rural areas in Nepal face the problem of spatial poverty trap with relatively better agroecological domain while peri-urban areas (PUAs) face the problem of agro-ecological degradation due to imprudent use of agro-chemicals particularly in the market oriented vegetable production (Bhatta, 2010). Use of agro-chemicals shows spatial relationship, households with road and market access use more agro-chemicals (Brown, 2003) and such spatial tendency gives rise to various farming practices (Bhatta et al., 2009a). The scientific findings on deleterious effects of excessive use of agro-chemicals on human, animal and the environment health have been reported frequently. While these problems are more acute in the highly intensive vegetable production areas (Bhatta et al., 2009b), organic or sustainable family farms enjoy better agro-ecological conditions (Sharma, 2006). Because of higher population pressure and less farm land availability along with efficient input-output marketing, peri-urban areas (PUAs) face acute problem of environmental degradation.

Urban areas in Nepal including Kathmandu valley have huge daily demand of the perishable commodities like vegetables and hence most of the farmers around urban and peri-urban areas are going towards commercial production of the vegetables (Bhatta, 2009). Close to $23 \%$ of the vegetables consumed in Kathmandu are produced by poor farmers in urban and peri-urban agricultures. This figure can be improved to $76 \%$ by improving farming practices and constructing a road networking system from the peri-urban to urban area (Pradhan and Parera, 2005). Most of the poor farmers in the PUAs make their living by selling vegetables in the market. This also contributes toward self-reliance in food and maintains the green

\footnotetext{
1 Agriculture, Scientific Staff and Ph. D. Scholar at Ins. of Agri. Eco. , Uni.versity of Hohenheim, Germany, Email: bhattagopal@gmail.com

${ }^{2}$ Professor at Ins. of Agri. Eco. , Uni. of Hohenheim, Germany, , Email: doppler@uni-hohenheim.de
} 
space in the Valley. Unfortunately, farmers around the hinterlands have been transforming their lands from subsistence based food production towards commercial farming of vegetables using agro-chemicals leading to the environmental cost of farming practice.

Realizing the negative repercussion of the external input based farming, some of the farmers nearby urban areas started following organic farming. The rural area, some 20-30 $\mathrm{km}$ away from Kathmandu metropolis, however, is dominantly occupied with subsistence farming more precisely considered to be organic by neglect. Variation in farming practices followed by the farmers in different spatial locations produce different socio-economic and environmental implications (Bhatta et al., 2009a). Recently there has been a tremendous increase in the utilization of GIS into analysis of socio-economic phenomena (Bowers and Hirschfield, 1999; Joshi et al., 1999; Schreier and Brown, 2001; Evans and Moran, 2002; KC, 2005; Codjoe, 2007; Bhatta et al., 2009a). Collecting socio-economic data in the spatial context and maintaining the original location specific information could reveal patterns in the data, which would otherwise be missed (Brown, 2003).

Socio-economic differentiation along the spatial gradient arises owing to the distances between fields, markets, access to information and location for off-farm opportunities. Biophysical settings of the resources and the socio-economic characteristics of the farm families can be influenced by their spatial position (KC, 2005). Location specific information for an entire region is best handled by computerized information system with the use of GIS. GIS software provides tools for the display and analysis of spatial information (Starr and Estes, 1990). It stores geographic data, retrieves and combines this data to create new representation of geographic space, provides tools for spatial analysis and performs simulations to help expert users organize their work in many areas including transportation, agriculture development and environmental information system (Rigaux et al., 2002). This research is based on the concept of spatial assessment of farm practices and socioeconomic attributes of farm families by integrating micro-survey in GIS environment and evaluating these aspects spatially in the regional level.

\section{METHODOLOGY}

\section{THE STUDY AREA}

Based on the research objectives, study area lying in Lalitpur and Bhaktapur districts in the mid hill of Nepal was selected (Fig.1) because of following reasons.

$>$ This area since historic time has been dominated by farming activity.

$>$ Vegetable production is commercialized and a large chunk of vegetable in the Kathmandu valley has been supplied by the farmers of this area.

$>$ Though not too far in terms of distance from capital city, some villages within the districts are less developed with unique rural setting and some villages are quite prosperous with modest accessibility and urban flavour.

$>$ Spatial variation is quite high in the selected areas and different farming practices have been performed by the farmers in different locations.

\section{SAMPLING PROCEDURE}

Before taking samples, three homogenous farming zones were identified viz., subsistence farming in the rural area, commercial inorganic farming in the North West and 1smallholder organic farming in the North East of the peri-urban areas of Lalitpur and Bhaktapur districts. Through spatial sampling, a total of 60 and 35 farm households were selected

\footnotetext{
${ }^{1}$ Many farms in the smallholder organic zone have a two-tier production system: organic for income generating crops like vegetables mostly in the kitchen garden and conventional for subsistence production of food crops.
} 
respectively from subsistence and commercial inorganic farming zones while 35 farm households from smallholder organic farming zone were selected by employing simple random sampling method. Spatial sampling was employed since information on the number of households settled down in the study areas was not available and at the same time wide physical coverage and scattered residence. Spatial sampling is based on the concept of spatial dependency which relies on the principle of proximity of locations to one another. Closer locations to one another are expected to have more similar values than those farther away (Tobler, 1970). The selection of this method was based on the principle that all households settled down in the study area were surveyed.

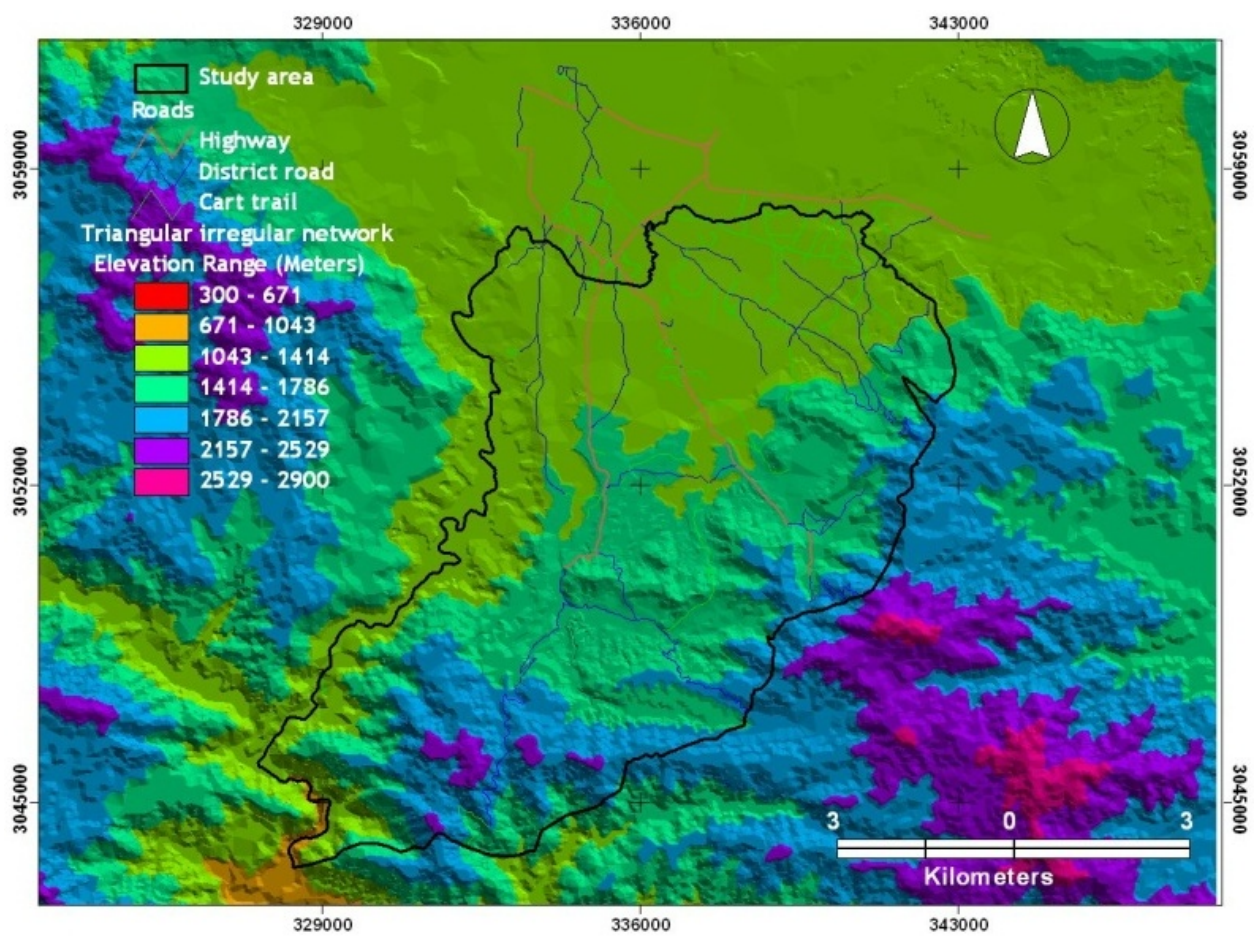

Fig. 1: Study area showing different farming zones and sampled household location at different altitudinal range indicated by Digital

\section{DATA COLLECTION}

Socio-economic data were collected using structured questionnaire devised after pretesting and administered through personal interview. Different analogue maps were purchased from Nepal Department of Survey and baseline GIS data for the study area was prepared using such maps. These maps cover roads, rivers and streams, settlements, administrative boundary, contour lines (100 m spacing) and elevations. Global Position System (GPS) was used to locate the household spatially.

\section{DATA INTEGRATION AND SPATIAL DEPENDENCY}

The interdependencies between the farming populations and their spatial attributes can be determined through the combination of farming systems methodology (Doppler et al., 2009) which is complemented by information extracted from geographical sources (KC, 2005). Relevant socio-economic data were combined with the spatial data to find the geographical 
influence on farming systems development. GIS is both a database system with specific capabilities for spatially referenced data, as well as a set of operations for analyzing the data (Star and Estes, 1990).

The strength of GIS lies in its ability to integrate different types of data into a common spatial platform. This information should present both opportunities and constraints for the decision makers (Ghafari et al., 2000). The ability of GIS to integrate maps and databases, using the geography as the common feature has been extremely effective in the context of agriculture development and resource management. The integration of data provides the ability to answer complex spatial questions that could not be answered otherwise (Buckley, 1997; Brown 2003). For linking socio-economic data with GIS, geographic locations of the sampled households was taken during field survey using GPS. After linking the GPS receiver to a computer, the recorded data were exported into Arc View 3.3. GIS software has the capability to deal with these "many-to-one" relationships, as well as the more common "one-to-one" relationships (Walsh et al., 2004). A common key field using household number was made for point attribute table in GIS and the survey databank. Once a linking field, known as the primary key, has been set up with household number, data were integrated and a relational database was obtained. Once data were integrated, they were subjected to spatial autocorrelation (SAC) and those variables confirming strong spatial dependency were finally used for spatial interpolation (Fig.2).

There are two popular indices for measuring SAC in a point distribution: Geary's Ratio and Moran's/both of which measures spatial dependency for interval or ratio data (Lee and Wong, 2001). Both Geary's Ratio and Moran's/combine the two measures for attribute similarity and location proximity into a single index of $\sum_{i=1}^{n} \sum_{j=1}^{n} c_{i j} w_{i j}$. It is used as the basis of formulating both indices. In both cases, the SAC is proportional to the weighted similarity of attributes of points which could be expressed as (Lee and Wong, 2001):

$$
\mathrm{SAC}=\frac{\sum_{i=1}^{n} \sum_{j=1}^{n} c_{i j} w_{i j}}{\sum_{i=1}^{n} \sum_{j=1}^{n} w_{i j}}
$$

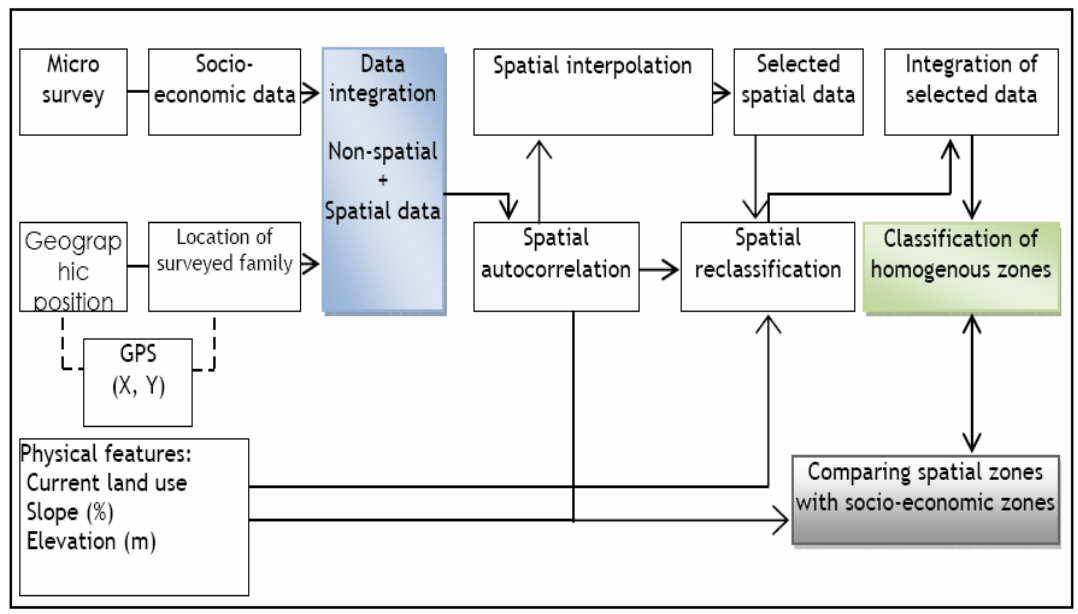

Fig. 2: Integration of socio-economic and biophysical data in GIS environment and process of spatial zoning (Modified from Bhatta et al., 2009a) 
Where, cij: similarity of point i's and point j's attributes; wij: proximity of point i's and point j's locations with wij= 0 for all points; xi: the value of the attribute of interest for point $\mathrm{i}$, and $\mathrm{n}$ : number of points in the point distribution

Fig.2 depicts the simplified flow diagram of all the steps of data integration into GIS environment. Only selected socio-economic variables were integrated in the GIS. Physical aspects such as land use, slope map and elevation were not analyzed spatially in this paper but nevertheless they crop up in the discussion. Most of the variables interpolated in the results and discussion section show strong spatial dependency.

\section{SPATIAL INTERPOLATION}

Spatial interpolation estimate the variables at unobserved locations in geo-space based on the values at observed locations (Zhang and Goodchild, 2002) thus it extrapolates a density estimate from individual data points. Although interpolation results are valid within the convex hull described by the sample locations, there is no way of confirming the true values of the field away from the control points so it is called a type of spatial prediction (O'Sullivan and Unwin, 2003). The principle that underlies all spatial interpolation is the Tobler Law- points which are close together in space tend to have similar value attributes. Basic methods include inverse distance weighting (IDW), spline, kriging and trend interpolation (Naoum and Tsanis, 2004). This study employed IDW which is one of the oldest and simplest approaches and is thus perhaps the most readily available method (Longley et al., 2004). IDW is based on the weights, which are inversely proportional to the square of the distance from the centre of the zone of interest (Kemp, 2008). Thus points closer to the location of estimation are weighted greater than those farther away. Output grid surfaces were created in which value of each cell ( 25 meter size) was calculated considering the values of 12 neighboring sample points and their distance to the point of estimation. A linear trend in the sample data was assumed for the model.

IDW method has been explained using Fig.3. Graphically, + is assumed to be the point of interest, $x i\left({ }^{*}\right)$ are the points where measurements were taken in which i runs from 1 to $n$, if there are $n$ data points (Fig.3), $z(x)$ denotes the unknown value and known measurements as $i$ a weight di, which will be evaluated based on the distance from $x i$ to $x$. Then the weighted average computed at $x$ is:

$$
\mathrm{Z}(\mathrm{x})=\sum_{i} w_{i} x_{i} / \sum_{i} w_{i} \quad \ldots \ldots \ldots(2) \quad \text { wi }=1 / d^{2}
$$

There are various ways of defining the weights, but the option most often employed is to

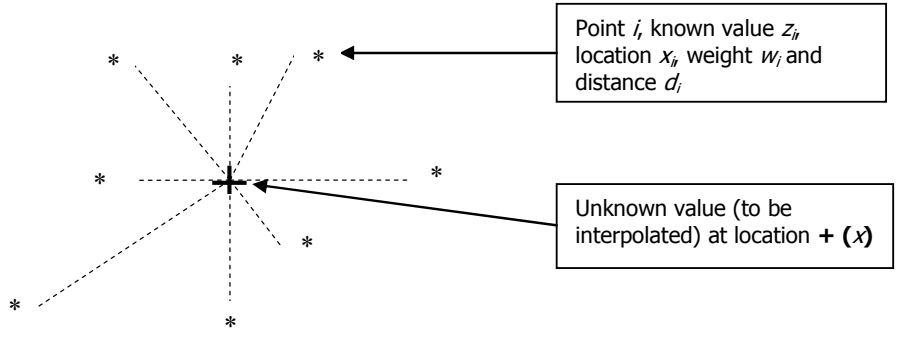

compute them as the inverse of squares of distances which means that the weight given to a point drops by a factor of four when the distance to the point doubles.

Fig. 3: Notation used in the equations in defining spatial interpolation (Source: Longley et al., 2004) 


\section{DATA ANALYSIS}

Descriptive statistical methods like means and confidence interval of means were employed. Mann-Whitney test was used for those sets of data which violated assumption of normality while ANOVA was used for normally distributed data. Confidence interval was fixed at $95 \%$. The descriptive statistical analysis along with parametric and non parametric tests for groups was done using SPSS 17.0. Pictorial presentation was done using SigmaPlot 10.0. Arc View 3.3 and Arc GIS 9.2 were employed for spatial explicit analysis.

\section{RESULTS AND DISCUSSION}

\section{SOCIO-ECONOMIC ATTRIBUTES}

This section illustrates the socio-economic characteristics of the farm families mainly family size, education, labour availability, land holding, livestock units and family income in different farming areas and along the spatial gradient.

\section{FAMILY SIZE}

The results show that average family size is 7.04 in subsistence farming, 5.58 in commercial inorganic farming and 5.86 in organic vegetable farming (Fig.4). In the national level,

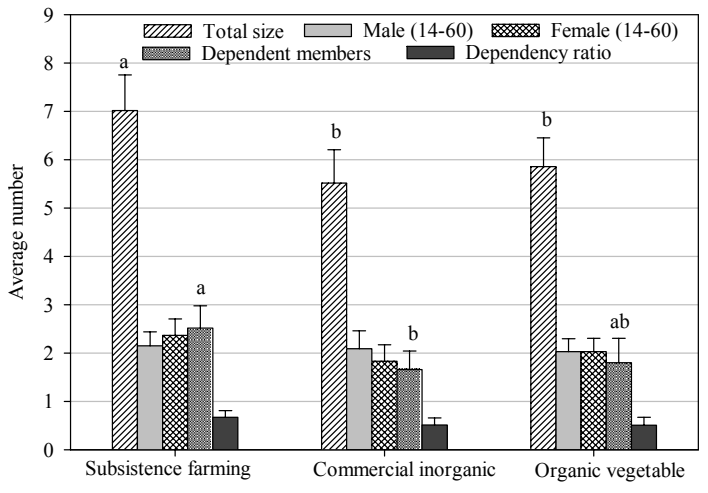
average family size is 5.4 (CBS, 2007) while it is 5.36 in rural areas (CBS, 2005), 5.47 in Bhaktapur district and 4.9 in Lalitpur district. The results from Mann Whitney test show that there is significantly higher family size in subsistence based farming as compared to others while agrochemical based and smallholder organic zones are on a par. The reason of higher family size in rural area is attributable to lower level of education and lack of awareness about family planning (CBS, 2005) and also the need of more family members for farm and household works.

Fig. 4: Distribution of family composition in different farming zones, 2008

Note: Error bar represents standard error of mean (SEm) and similar bars with identical letters are not significantly different between the group at 0.05 level of probability according to the Mann-Whitney test

Higher dependency ratio, a measure of the portion of a population which is composed of dependents (who are too young or too old to work), is of concern since dependents do not contribute economically but share economic resources of the household (Blair, 2007). Under the circumstances of extreme limitations of such resources, an elevated dependency ratio would obviously exacerbate poverty. In the national level, dependency percentage is 77.23 while in rural areas it goes as high as $94.90 \%$ (CBS, 2007). Dependency ratio, albeit higher in the subsistence farming, is not significantly different from others. Large family size coupled with higher dependency ratio in the rural subsistence area brings the lower level of living standard as population has been increasing and resources have been degrading leading to demand of more food from the external source.

The results of the spatial distribution of family size observed using GIS methodology through interpolation of micro level information demonstrate the variation of family size along the spatial gradient (Fig.5). It is seen that higher family size is found in the less accessible area 
where subsistence farming predominates and family size starts declining towards accessible zones. Spatial variation in family size is mainly due to the availability of infrastructures, awareness and literacy status of the family members.

\section{EDUCATIONAL STATUS}

Education is one of the preconditions for development. Education grooms the mind and makes it receptive to technological innovation (Ayandiji et al., 2009). Indictors of economic well being such as farm productivity and income is related to educational affluence of the adults in the family (Brown, 2003). The empirical results show that the educational status of the farmers in the study area is better in urban fringe as compared to the peri-urban fringe (Fig.6). Family members with college level of education differ significantly between

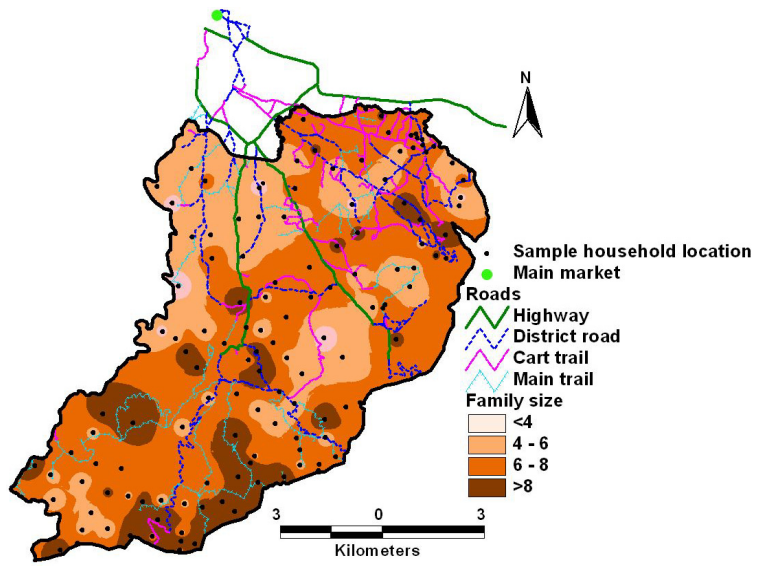
the groups. The lower level of education in subsistence group is due to less access to educational institution, inability to afford for higher education generally available in the city cores and requirements of more labor force in household and farm activities. Lower level of education in subsistence farming area might lead to poor receptivity of innovative production practices. Family members with low level of education feel difficulty in understanding technological complexity and the benefit from new technology.

Fig. 5: Spatial distribution of family size along the spatial gradient

\section{FAMILY LABOUR FORCE}

Mean family labour for household work is significantly higher in smallholder organic group as compared to commercial inorganic farming and is on a par with that of subsistence group. Contrastingly the mean family labour for farm work is significantly higher in rural area as compared to that in the peri-urban areas (Table 1). Higher number of males and females are involved in off-farm activities in smallholder organic group which is basically due to higher level of education coupled with availability of off-farm opportunities nearby and tendency of both males and females to be economically independent.

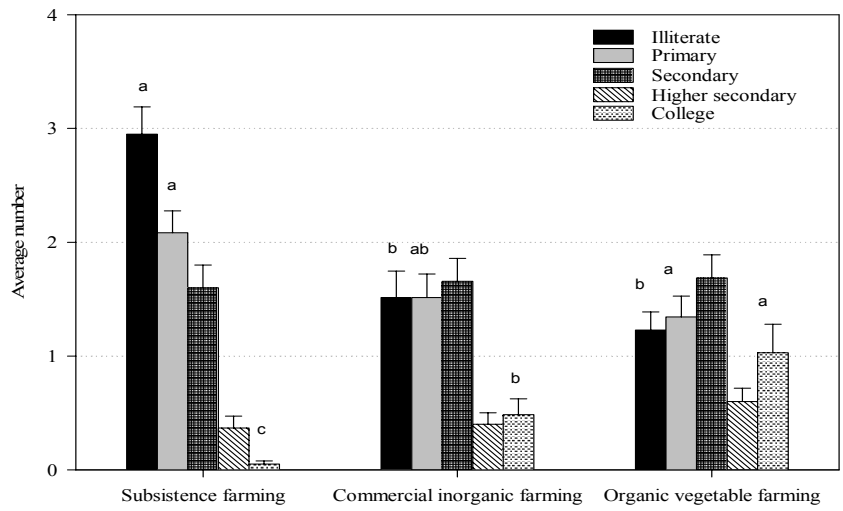

Fig. 6: Educational status of the family members by study zones, 2008 
Note: Error bar represents standard error of mean (SEm) and similar bars with identical letters are not significantly different between the group at 0.05 level of probability according to the Mann-Whitney test.

Number of family members involved in own enterprise becomes lower in relatively less accessible area. In contrast, number of family members as labourers is higher in the subsistence farming. Requirements of more farm laborers, unavailability of the off-farm opportunities, less education and remoteness are all contributing towards this. Involvement of more members as farm labors means less income as wage rate is meager leading to poor living standards of the farm families in the remote areas.

Table 1: Mean family labor in farm, household and off-farm activities by study zones

\begin{tabular}{llll}
\hline \multicolumn{1}{c}{ Labour capacity } & \multicolumn{1}{c}{$\begin{array}{c}\text { Subsistence } \\
\text { farming }(\mathrm{n}=60)\end{array}$} & $\begin{array}{c}\text { Commercial inorganic } \\
(\mathrm{n}=35)\end{array}$ & $\begin{array}{c}\text { Smallholder organic } \\
(\mathrm{n}=35)\end{array}$ \\
\hline Household work & $2.97^{\mathrm{ab}}( \pm 0.30)$ & $2.49^{\mathrm{b}}( \pm 0.36)$ & $3.37^{\mathrm{a}}( \pm 0.51)$ \\
Farm work & $3.70^{\mathrm{a}}( \pm 0.33)$ & $3.00^{\mathrm{b}}( \pm 0.44)$ & $3.50^{\mathrm{ab}}( \pm 0.46)$ \\
Males in off-farm work & $0.97( \pm 0.22)$ & $0.83( \pm 0.28)$ & $1.20( \pm 0.31)$ \\
Females in off-farm work & $0.19^{\mathrm{b}}( \pm 0.19)$ & $0.54^{\mathrm{b}}( \pm 0.26)$ & $0.77^{\mathrm{a}}( \pm 0.25)$ \\
Total off-farm work & $1.43( \pm 0.34)$ & $1.37( \pm 0.43)$ & $1.97( \pm 0.48)$ \\
$\quad$ Own enterprise & $0.18^{\mathrm{b}}( \pm 0.14)$ & $0.23^{\mathrm{b}}( \pm 0.19)$ & $0.54^{\mathrm{a}}( \pm 0.29)$ \\
$\quad$ Salaried work & $0.78^{\mathrm{b}}( \pm 0.23)$ & $0.89^{\mathrm{b}}( \pm 0.29)$ & $1.29^{\mathrm{a}}( \pm 0.35)$ \\
$\quad$ Laborers & $0.47( \pm 0.24)$ & $0.26( \pm 0.21)$ & $0.17( \pm 0.58)$ \\
\hline
\end{tabular}

Note: Figures in parentheses are $95 \%$ confidence interval of the mean; Letters in the superscript show the significant difference between groups at 0.05 level of probability according to the Mann-Whitney test and values with similar letters are not significant

\section{LAND AREA AVAILABILITY}

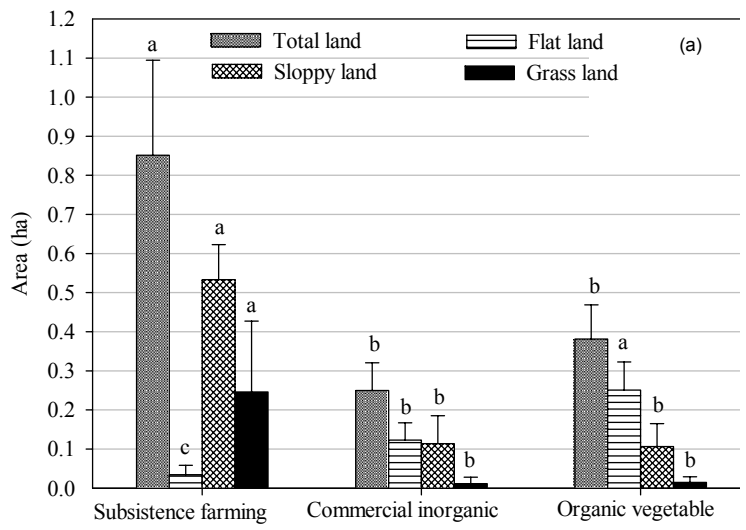

Quality and quantity of land availability determine the living standard of farm families. Moreover, type of crops grown on it, productivity and market value of the produce largely shapes the family's living standards. The results show that average land holding is substantially higher in the subsistence farming followed by the smallholder organic farming (Fig.7a). Although land availability in rural area is higher, production potential of land is lower. Land in the urban area is very inelastic in supply and it has huge economic value.

Fig. 7a: Average land area (ha) under different types of land.

Note: Error bar represents standard error of mean (SEm) and similar bars with identical letters are not significantly different between the group at 0.05 level of probability according to the Mann-Whitney test.

Average land holding size in the Kathmandu Valley is 0.26 ha (CBS, 2003) while it is 0.25 , 0.31 and 0.23 ha respectively in Kathmandu, Lalitpur and Bhakapur districts and these values are quite smaller against average land holding size in Nepal which is 0.80 ha (CBS, 2006). Average land holding per family in the subsistence area is almost equal to the national average while other two zones have land size almost equal to that of Kathmandu 
valley. Significantly higher area under maize is found under subsistence farming zone. This is obvious because most of the land is sloppy and maize is most important food and feed crop in this zone. Most of the lands are rainfed in which rice could not be grown successfully. Similar to this is the area covered by mustard and legumes. Significantly higher area under different kinds of vegetables is found in smallholder organic zone as compared to the subsistence farming and former is on a par to commercial inorganic

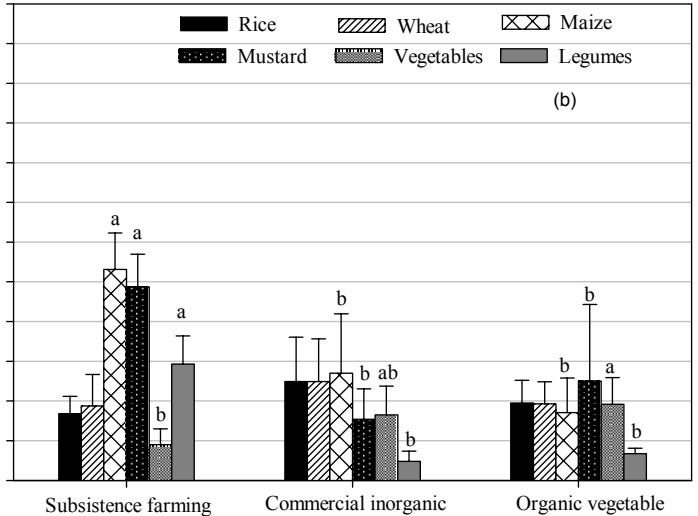
farming (Table $7 \mathrm{~b})$. Farmers in the subsistence farming produce vegetables in kitchen garden mainly for home consumption. Farmers nearby market centre have tendency to grow vegetables commercially and derive income. This is the reason why there is more area under vegetables in peri-urban hinterlands.

Flat land availability is significantly higher in the smallholder organic area as compared to others while sloppy land (bari land), forest and grazing land are significantly higher in the subsistence farming zone.

Fig. 7b: Average land area (ha) under different crops.

Note: Error bar represents standard error of mean (SEm) and similar bars with identical letters are not significantly different between the group at 0.05 level of probability according to the Mann-Whitney test.

Food crop area, which includes the area of rice, wheat, maize, potato, buckwheat, mustard and some minor food crops, illustrates the conspicuous pattern along the spatial gradient (Fig.8). Households with poor access to infrastructures have larger holdings and more reliant on subsistence agriculture. Households with road access have smaller landholdings

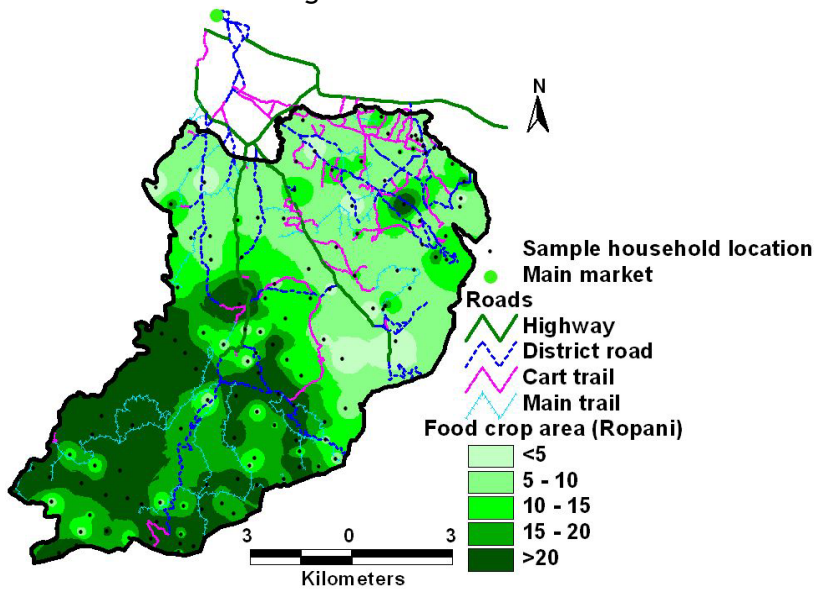
and are more reliant on off-farm employment to meet their families' needs. Brown (2003) noted similar spatial tendency of landholdings in mid hill of Nepal. In the accessible area of Kathmandu valley, land is extremely expensive and it has alternative use for settlement. Therefore people would not like to follow agriculture but would be interested to earn huge money by selling smaller parcels.

Fig. 8: Spatial distribution of food crops area (interpolation of the point based data) 


\section{TROPICAL LIVESTOCK UNIT}

Livestock unit measured as the number of animals per farm has an inherent weakness in that as it ignores species and age groups (Katwijukye, 2005). Therefore, the available animal units in the study area are expressed in standardized term called Tropical Livestock Unit (TLU). This parameter is adopted because it allows pooling together animals of different age group and species and gives a relative figure for computation (Kaburanyaga, 2007). Spatial distribution of TLU shows clear variation in the space. Clustering of higher

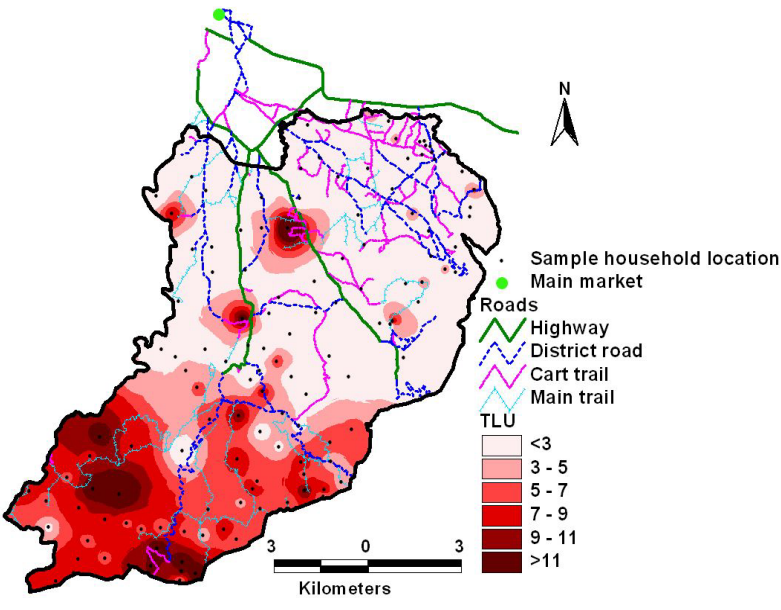

TLU is found in the rural areas and it goes on decreasing from remote to urban areas (Fig.9). In urban areas, generally buffaloes are not reared and some farmers do have few units of poultry generally for home consumption. The reverse is true in remote area where mostly farmer rears cow, buffaloes and goats for market as well as for home consumption and poultry for home consumption. Integration of livestock with agriculture and forest is one of the fundamental aspects of sustainability of the rural farming.

Fig. 9: Spatial distribution of the livestock units in terms of TLU

\section{FAMILY INCOME}

Family income was calculated by considering revenues and expenses of all farm activities, off-farm income and income from other sources. Spatial clusters of family incomes are found in the study area. It is relatively lower along the higher altitudinal gradient and it becomes higher in the flat land nearby urban centres (Fig.10). The higher family income towards urban and peri-urban areas is basically due to more off-farm income. Accessibilities to the urban amenities along with the availability of the off-farm opportunities bring higher level of income in the urban areas. Rural areas mainly depends on farm income and because of subsistence mode of production, farm income is also lower in the rural area. Lower farm income, lack of off-farm opportunities along with relative inaccessibility put rural farmers under the spatial poverty trap (Bhatta, 2010).

\section{ENVIRONMENTAL ASPECTS OF FARM PRACTICES}

Overall response of the farmers shows declining that there has been a trend in the crop yield irrespective of the production zones (Table 2). Most of the farmers asserted that organic farming is the key for restoring fertility. Most of the smallholder organic growers after realizing the negative repercussion of inorganic farming shifted to this practice of production. Farmers in the commercial inorganic zone experiences negative repercussion of agro-chemicals on the environment. The use of agro-chemicals particularly in the market based vegetable production in this zone is imprudent. Farmers who own livestock apply the manure along with the inorganic fertilizers while those don't own livestock solely depends on inorganic fertilizers as the source of nutrients which is detrimental for the edaphic environment. Although the upward trend in yield of rice-wheat cropping pattern has been maintained over the two decades in the inorganic farming zone, the rate of increase is 
slackening, largely because of deteriorating soil fertility and the high incidence of pests and diseases associated with monoculture.

Table 2: Yield reduction in farm (\% of the respondents)

\begin{tabular}{lrrr}
\hline $\begin{array}{l}\text { Yield } \\
\text { reduction }\end{array}$ & $\begin{array}{r}\text { Subsistence farming } \\
(\mathrm{n}=60)\end{array}$ & $\begin{array}{r}\text { Commercial inorganic } \\
(\mathrm{n}=35)\end{array}$ & Organic vegetable $(\mathrm{n}=35)$ \\
\hline Yes & 83.3 & 62.9 & 85.7 \\
No & 16.7 & 37.1 & 14.3 \\
\hline
\end{tabular}

Most of the farmers in organic and commercial inorganic farming experience sharp declination in the yield of rice-wheat cropping pattern whilst farmers of subsistence farming zone experience the yield declination of maize-mustard cropping pattern in which mustard yield has been declining substantially over the last few years owing principally to degrading soil fertility, disease and pest infestations and heavy wind which causes erosion of available nutrients from the surface. In the area where urea fertilizer has been applied constantly without considering soil's contribution and its unbalanced use has led to deficiency of micro-nutrients such as sulphur. Main limiting factors of yield declination are lack of irrigation, unbalanced use of agro-chemicals especially urea and pesticides, soil

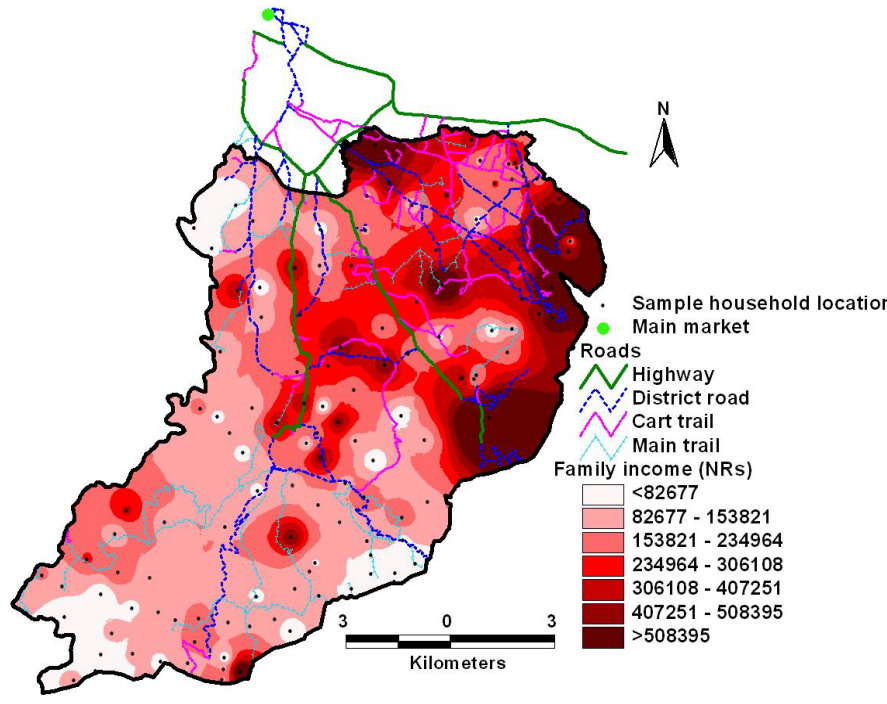
erosion in sloppy land, disease and pest infestation and lack of manure among others (Fig.11). Principal reasons of yield declination in subsistence farming are lack of irrigation and effect of diseases and pest. Among different diseases, maize blight is the severe disease of maize while aphid is the main pest of mustard. Farmers have also noted the problem of unbalanced use of agro-chemicals which are generally used in vegetables.

Fig. 10: Spatial distribution of family income (NRs) in the study area, 2008

Overuse of agro-chemicals such as urea nitrogen and pesticides in food and vegetable crops is the main limiting factor in commercial inorganic farming. Farmers in this region are fully dependent on inorganic fertilizers and they give less credence to the farm manure. In addition, farmers, with the hope of getting high yield in short period of time, apply huge amount of pesticides for controlling pests and diseases. Therefore, unbalanced use of agrochemicals is one of the key environmental issues in this area.

Disease and pest is becoming main reason for declining yield in the smallholder organic farming as most of the farmers produce organically in which they apply local materials specifically botanicals to control pest and disease which are not as efficient as pesticides. Henceforth farmers have to incur a huge loss of the produce each year. Along with this is the unbalanced use of agro-chemicals which is still being practiced by some farmers. Similar to commercial inorganic farming zone, mostly farmers do not own livestock and 
therefore, farmers have to depend on others for the supply of required amount of organic manure for the crops. The main sources of nutrient are farm manure, poultry manure, cakes and kitchen waste among others.

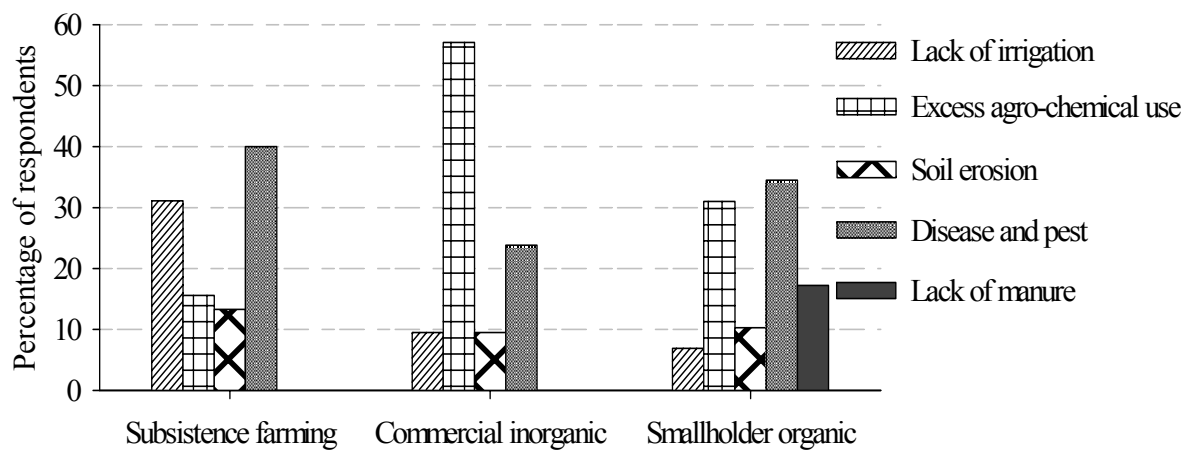

Fig. 11: Reasons of yield declination in different farming areas

Constraints of production practices identified by farmers in different areas at household and in regional levels provide an interesting example of the relevance of maintaining spatial integrity in socio-economic data. Farmers in the accessible commercial vegetable production area identified problem of excessive use of agro-chemicals followed by disease and pest as immediate constraints faced by farming households. When examined spatially, it is clear that both issues are relevant but in different spatial locations. Disease and pest is most pronounced constraint in the rural areas with relative inaccessibility and also in organic production area while issue of agro-chemicals is imprudent in the intensive inorganic based farming areas.

\section{CONCLUSION}

Maintaining spatial integrity in socio-economic data collection, analysis and presentation permits a deeper understanding of socio-economic interactions than traditional methods used by most of the social scientists. Farming sector and its actors are much influenced by the spatial variation because of the need to stay contact with the market and other services. This is one of the main reasons why such a large chunk of so called 'organic by neglect' family farms in the rural area couldn't be converted to real organic. In the study area, accessibility towards basic infrastructure dividing whole area into peri-urban and rural setting has significant implications for employment opportunities, infrastructural support, agro-chemical availability, market access and dependence on subsistence farming along with variations in farming practices. Spatial variation leading to lack of off-farm employment, services, infrastructure and improved input and subsistence farming makes rural area a vulnerable place to live in. Nevertheless, natural environment with scenic beauty and social harmony should also be reckoned with. The low lying valley hinterlands with good access to road and other infrastructures and access to the market makes this area an ideal place to live in but agro-ecological degradation should be taken into immediate concern. The finding supports that there is a significant effect of road and other infrastructures on socio-economic issues and farming differentiation. Spatial analysis of socio-economic data and farming practices has implications for policy and project development, particularly road and agriculture development projects. 


\section{REFERENCES}

Ayandiji, A., A. L. kehinde, O. R. Adeniyi and O. Omotosho, 2009. Gross margin analysis of post harvest losses in Citrus spp. in Ife ADP zones of Osun State, Nigeria. Journal of Agricultural Extension and Rural Development, 1(3):77-84.

Bhatta G. D., W. Doppler and K. B. KC, 2009a. Spatial differentiation in farming practices and their impact on rural livelihood, a case from hills of Nepal. In: E. Tielkes (ed.), Book of Abstract, International Research on Food Security, Natural Resource Management and Rural Development, Hamburg, Germany.

Bhatta, G. D., 2009. Consumer willingness to pay and preference towards vegetable attributes at Kathmandu valley: A conjoint approach. Paper presented at the $2^{\text {nd }} \mathrm{Ph} \mathrm{D}$ Conference in Economics at Athens, Greece on 14-15 May 2009.

Bhatta, G. D., W. Doppler and K.B. KC, 2009b. Potential of organic agriculture in Nepal. Journal of Agriculture and Environment, 10:1-11.

Bhatta, G.D., 2010. Bio-farming and marketing in Nepal: through producer, consumer, trader and spatial perspectives. In: W. Doppler and K.B. KC (eds.), Farming and Rural Systems Economics and Biodiversity in the Tropics, Margraf Publishers, Germany.

Blair, R. A., 2007. An assessment of agricultural risk and diversification on farming families' living standard under fuzzy conditions. A case from Guyana. Weikersheim, Germany: Margraf Verlag.

Bowers, K. and R. Hirschfield, 1999. Exploring links between crime and disadvantage in northwest England: an analysis using geographic information systems. International Journal of Geographic Information Science, 13: 159-184.

Brown, S., 2003. Spatial analysis of socio-economic issues: gender and GIS in Nepal. Mountain Research and Development, 23(4):338-344.

Buckley, D. J., 1997. The GIS primer: An introduction to geographic information systems. Pacific Meridian Resources, Inc.

CBS, 2003. Population monograph, 2003. His Majesty's Government, NPCS, Central Bureau of Statistics, Kathmandu, Nepal.

CBS, 2005. Nepalese Living Standard Survey 2003/04: Statistical Report II.

CBS, 2006. Monograph, Agriculture Census Nepal 2001/02. HMG/NPCS, Central Bureau of Statistics, Kathmandu, Nepal.

CBS, 2007. Statistical Year Book of Nepal 2007.

Codjoe, S. N. A., 2007. Integrating remote sensing, GIS, census and socioeconomic data in studying the population-land use/cover nexus in Ghana: A literature update. Africa Development, 32(2):197-212.

Doppler, W., K.B. KC and J. Kitchaicharoen, 2009. Water resources development and its impact on rural livelihood in Northern Thailand: Integrating GIS into farming systems economics. Weikersheim: Margraf Publishers.

Evans, T. P. and E. F. Morans, 2002. Spatial integration of social and biophysical factors related to landscape change. Population and Development Review, Supplement to Vol 28.

Ghafari, A., H. F. Cook, and H. C. Lee, 2000. Integrating climate, soil and crop information: A land suitability study using GIS.

Joshi, P. K., S. Pande, M. Asokan, 1999. Socioeconomic dataset and use of GIS. In: Pande S, Johansen C, Lauren J, Bantilan FT Jr, editors. GIS Analysis of Cropping Systems. New York: ICRISAT and Cornell University, pp 55-63.

Kaburanyaga, E. A., 2007. Smallholder cash crop production and its impact on living standards of rural families in Kenya. Margraf Publishers.

Katwijukye, A.K., 2005. Socio-economic analysis of land resource use and conservation in Uganda. Margraf Publishers.

KC, K. B., 2005. Combining socio-economic and spatial methodologies in rural resources and livelihood development: A case from mountains of Nepal," Wekersheim: Universität Hohenheim, Margraf Verlag.

Kemp, K. K., 2008. Encyclopedia of geographic information science. California: Sage Publications. 
Lee, J., and D. S. Wong, 2001. Statistical Analysis with Arcview GIS. New York: John Wiley and Sons Inc.

Longley, P. A., M. F. Goodchild, D. J. Maguire and D. W. Rind, 2004. Geographic Information Systems and Science. John Wiley and Sons Ltd.

Naoum, S., and I. K. Tsanis, 2004. Ranking spatial interpolation techniques sing a GIS-based Dss, Global Nest, 6, 1-20.

O'Sullivan, D., and D. Unwin, 2003. Geographic Information Analysis. John and Wiley and Sons Inc.

Pradhan, P. and R. Perera, 2005. Urban growth and its impact on the livelihoods of Kathmandu Valley, Nepal. Urban Management Programme for Asia and the Pacific, Urban Resource Network for Asia and Pacific.

Rigaux, P., M. Scholl and A. Voisard, 2002. Spatial database with application to GIS. Morgan Kaufmann Publishers, An Imprint of Elsevier, San Francisco.

Schreier, H. and S. Brown, 2001. Scaling issues in watershed assessments. Water Policy, 3:475-489.

Sharma, G., 2006. Organic Agriculture in Nepal: An Analysis in to Status, Policy, Technology and Psychology. In: Sharma, G. and P. B. Thapa (eds.) Proceedings of National Workshop on Organic Agriculture and Farming System, Nepal Permaculture Group, Kathmandu, Nepal.

Starr, J. and F. Estes, 1990. Geographic information systems: an introduction. Englewood Cliffs, Prentice Hall.

Tobler, W. R., 1970. A computer movie simulating urban growth in the detroit region,"Economic Geography, 234-240.

Walsh, S. J., R. E. Bilsborrow, S. J. McGregor, B. G. Frizzelle, J. P. Messina, W. K. T. Pan, K. A. CrewsMewer, G. N. Taff, and F. Baquero, 2004. Integration of longitudinal surveys, remote sensing time series and spatial analyses, New York: Kluwer Academic Publishers.

Zhang, J., and M. F. Goodchild, 2002. Uncertainty in geographical information. London: CRC Press.

\section{ACKNOWLEDGEMENT}

Financial support provided by the DAAD to pursue this research is highly acknowledged. We also express our thanks to the anonymous reviewer for providing the expert ideas and making this paper more contextual. 